J Am Chem Soc. 2019 October 02; 141(39): 15466-15470. doi:10.1021/jacs.9b05725.

\title{
Engineering Methyllysine Writers and Readers for Allele-Specific Regulation of Protein-Protein Interactions
}

\author{
Simran Arora, W. Seth Horne, Kabirul Islam* \\ Department of Chemistry, University of Pittsburgh, Pittsburgh, Pennsylvania 15260, United States
}

\begin{abstract}
Protein-protein interactions mediated by methyllysine are ubiquitous in biological systems. Specific perturbation of such interactions has remained a challenging endeavor. Herein, we describe an allele-specific strategy toward an engineered protein-protein interface orthogonal to the human proteome. We develop a methyltransferase (writer) variant that installs aryllysine moiety on histones that can only be recognized by an engineered chromodomain (reader). We establish biochemical integrity of the engineered interface, provide structural evidence for orthogonality and validate its applicability to identify transcriptional regulators. Our approach provides an unprecedented strategy for specific manipulation of the methyllysine interactome.
\end{abstract}

Lysine methylation in histones is a post-translational modification that regulates gene expression. ${ }^{1}$ This process is catalyzed by lysine methyltransferases (KMTs), classified as "writers", using S-adenosylmethionine (SAM) (Figure 1). ${ }^{2,3}$ Biological functions of methyllysine are manifested via specific recognition by conserved protein modules termed "readers" (Figure 1). ${ }^{4-6}$ In humans, an array of $\sim 60$ KMTs and $>200$ proteins with reader domains are involved in establishing and recognizing $>5000$ methyllysine sites. ${ }^{7}$ Contextdependent function of the methyllysine network is largely unexplored, mainly due to a lack of tools capable of interrogating various components of the "interactome" simultaneously. 8-10 Probing how a specific writer-histone-reader axis contributes to chromatin-dependent processes requires precise and sequential perturbation of the methyllysine writers and readers.

Allele-specific chemical genetics (often called the "bump-and-hole" tactic) has emerged as a powerful tool to examine member-specific protein function. ${ }^{11-16}$ We envisioned developing allele-specific writer-histone-reader pairs, fully orthogonal to the human proteome, for precise manipulation of methyllysine interaction (Figure 1). We reasoned a "hole-modified" KMT could accept SAM analogues to modify histone with bulky groups that would perturb the binding of a wild-type reader through steric repulsion. Interaction with the "bumped" histone could be restored with a "hole-modified" reader variant, thus providing control over methyllysine-dependent interactions. Although engineered KMTs are known, ${ }^{17}$ evolving a

\footnotetext{
*Corresponding Author kai27@pitt.edu.

Supporting Information

The Supporting Information is available free of charge on the ACS Publications website at DOI: 10.1021/jacs.9b05725.

Methods for protein expression and crystallization, biochemical assays, supplementary figures and tables (PDF)

The authors declare no competing financial interest.
} 
reader to recognize non-native protein modifications is unexplored. We hypothesized that the hydrophobic "aromatic cage" in a reader domain that recognizes methyllysine ${ }^{5}$ could be expanded to accommodate alkyllysine in histone and create an orthogonal interface.

We chose trimethylation on $\mathrm{H} 3$ at lysine 9 (H3K9me3) as a host system to test the above approach. $\mathrm{H} 3 \mathrm{~K} 9$ methylation is a marker of transcriptional repression. ${ }^{1}$ In humans, a large set of KMTs methylate H3K9, and the modification is "read" by chromodomain and PHD finger containing proteins. ${ }^{5,18}$ Herein, we first develop "hole-modified" H3K9me3 methyltransferases, G9a and Suv39H2, to install lysine modifications that are not recognized by cognate wild-type readers $\mathrm{CBX} 1,3$, and 5 ; we go on to engineer CBX proteins that bind "bumped" histone and restore the lost interaction. Finally, we provide structural evidence for orthogonality and demonstrate suitability of the engineered system to control a methyllysine-dependent signaling pathway.

To access the "bumped" histone peptides, we synthesized a series of SAM analogues carrying bulky sulfonium alkenyl and aryl groups (Figure 2A, Scheme S1) ${ }^{17,19}$ Each of the SAM derivatives was incubated with previously developed Y1154A mutant of G9a ${ }^{17}$ and tetramethylrhodamine (TAMRA) labeled $\mathrm{H} 3 \mathrm{~K} 9$ peptide. The products were purified and confirmed by matrix assisted laser desorption/ionization mass spectrometry (MALDI-MS) (Figure S1). The mutant showed complete alkenylation of the substrate (Figure S1); however, it was not efficient at incorporating benzyl modification. We envisioned an aryl group as a lysine modifier would improve binding with engineered CBX by maintaining $\pi-$ $\pi$ interaction in the remodeled aromatic cage. We surmised that expanding the pocket of G9a further could facilitate its use of benzyl-SAM. Indeed, Y1154G mutation led to complete substrate benzylation (Figure 2B), demonstrating that G9a can be engineered to accept aryl SAM analogues for expanding the repertoire of "bumped" histone variants. Under our assay conditions, we did not observe any dibenzylation of the substrate by G9a mutant (Figure S2).

As a model reader domain for allele-specific engineering, we selected the CBX1 chromodomain, which recognizes $\mathrm{H} 3 \mathrm{~K} 9 \mathrm{me} 3$ through its aromatic cage. ${ }^{20}$ First, using a fluorescence polarization assay, we determined the dissociation constants $\left(K_{\mathrm{d}}\right)$ of wild-type CBX1 chromodomain from TAMRA-labeled $\mathrm{H} 3 \mathrm{~K} 9 \mathrm{me} 3$ and various "bumped" variants (Figure $2 \mathrm{C}, \mathrm{S} 3)$. The reader protein bound H3K9me3 tightly, with a $K_{\mathrm{d}}(2.0 \pm 0.1 \mu \mathrm{M})$ close to the reported value. ${ }^{21} \mathrm{CBX} 1$ showed 53-fold weaker binding affinity $K_{\mathrm{d}}=106 \pm 20 \mu \mathrm{M}$ ) toward allyl-modified peptide. Importantly, it failed to bind peptides with modifications bulkier than allyl ( $K_{\mathrm{d}}>500 \mu \mathrm{M}$, Figure S3), presumably due to a steric clash inside the aromatic cage.

In order to develop an orthogonal reader, we analyzed a published structure of the CBX1 chromodomain and identified residues Y26, W47, F50, D54 and T56 that recognize $\mathrm{H} 3 \mathrm{~K} 9 \mathrm{me} 3 .^{22}$ We generated the corresponding alanine mutants and measured their binding affinity toward all the modified peptides (Figure 2C, S4-8). Compared to wild-type CBX1, the mutants showed decreased binding toward the trimethylated peptide, indicating that an intact hydrophobic pocket is essential for optimum recognition of H3K9me3. ${ }^{21}$ Among the CBX1 mutants examined, F50A showed significant gain in binding affinity toward the 
pentenyl and benzyl peptides ( $K_{\mathrm{d}}$ of $14.1 \pm 2.8$ and $18.5 \pm 4.5 \mu \mathrm{M}$, respectively), while affinity for H3K9me3 decreased by almost 32 -fold $\left(K_{\mathrm{d}}\right.$ of $\left.63.5 \pm 6.2 \mu \mathrm{M}\right)$ compared to wildtype reader (Figure 2C, S6). Encouraged by this result, we prepared F50G mutant with a larger cavity in an effort to further improve the binding efficiency. F50G indeed showed a 3fold improvement in affinity toward H3K9bn (Figure 2C, S9).

To improve orthogonality of the engineered readers, we generated several double mutants by combining F50G with mutations at Y26. Most mutations led to complete loss of binding (Figure S10-12); however, a Y26F/F50G variant with intact aromatic side chain at F26 maintained robust affinity toward benzyl peptide $\left(K_{\mathrm{d}}=5.5 \pm 0.9 \mu \mathrm{M}\right.$; Figure $\left.2 \mathrm{C}, \mathrm{S} 10\right)$. Importantly, interaction with $\mathrm{H} 3 \mathrm{~K} 9 \mathrm{me} 3$ peptide was reduced to a $K_{\mathrm{d}}$ of $\sim 80 \mu \mathrm{M}$. We further confirmed the binding constants by isothermal titration calorimetry using $\mathrm{H} 3 \mathrm{~K} 9 \mathrm{me} 3$ and benzylated (H3K9bn) peptides. Both native and engineered readers showed comparable affinity to their cognate peptides (Figure 3A,B, S13, Table S1). Furthermore, when tested against the $\mathrm{H} 3 \mathrm{~K} 9 \mathrm{me} 2$ peptide, a major enzymatic product of $\mathrm{G} 9 \mathrm{a}$, wildtype and engineered CBX1 bound with $K_{\mathrm{d}}$ of $18.3 \mu \mathrm{M}$ and $>300 \mu \mathrm{M}$, respectively (Figure S14). Taken together, our mutational study led to an orthogonal chromodomain capable of recognizing "bumped" histone peptide—a new approach to modulate histone-reader interactions.

To gain further insight into the orthogonality of the bump-hole pair, we grew crystals of the complex of native CBX1 with $\mathrm{H} 3 \mathrm{~K} 9 \mathrm{me} 3$ as well as the complex of Y26F/F50G-CBX1 with H3K9bn by hanging drop vapor diffusion. We collected diffraction data on each complex, solved the native structure (PDB 6D07) by molecular replacement with a model derived from a structure of $\mathrm{CBX} 5$ bound to $\mathrm{H} 3 \mathrm{~K} 9 \mathrm{me} 3,{ }^{21}$ and solved the mutant structure (PDB 6D08) using the refined model of the native CBX1 complex. Both structures were refined to 2.1 A resolution (Figure 3C,D, Table S2). The overall fold and binding interactions observed for native $\mathrm{CBX} 1$ in complex with $\mathrm{H} 3 \mathrm{~K} 9 \mathrm{me} 3$ are identical to those noted in closely related members CBX3 and CBX5 (Figure S15). ${ }^{21}$ The backbone coordinates for the bump-hole mutant complex were virtually identical to native CBX1 (0.6 $\mathrm{C}_{a}$ rmsd, Figure S15). Inspection of the aromatic binding pocket shows that the benzyl "bump" effectively fills the hole created by the F50G mutation (Figure 3D) and that removal of the side chain in CBX1 has no measurable effect on local backbone conformation. Superimposition of the two complexes revealed that F50 of wild-type CBX1 undergoes steric interference with benzyl group of H3K9bn (Figure S15), explaining the observed orthogonality.

Sequence analysis of the major KMTs revealed that Y1154 in G9a is highly conserved among writers (Figure 4A) and an aromatic residue, equivalent to F50 in CBX1, is present in all of the readers analyzed (Figure 4B). ${ }^{23}$ These bulky amino acids are acting as gatekeepers that preclude binding of SAM and methyllysine analogues to writers and readers, respectively. We focused on another H3K9me3 methyltransferase, Suv39H2, and the cognate reader CBX3 ${ }^{24,25}$ The hole-modified Y372G mutant of Suv39H2, equivalent to G9a-Y1154G, efficiently utilized benzyl-SAM to modify substrate peptide as well as fulllength H3 (Figure 4C, S16, S17).

To demonstrate generality among reader domains, we prepared an F44G mutant of CBX3, equivalent to Y26F/F50G-CBX1. Conveniently, CBX3 already carries a phenylalanine at the 
position equivalent to Y26 in CBX1. Wild-type $\mathrm{CBX} 3$ recognized $\mathrm{H} 3 \mathrm{~K} 9$ me 3 peptide effectively as judged by fluorescence anisotropy, but no binding was observed toward the benzylated homologue (Figure 4D). In contrast, the "hole-modified" CBX3 exhibited enhanced affinity for $\mathrm{H} 3 \mathrm{~K} 9 \mathrm{bn}$ with significant loss of binding toward the trimethyl mark (Figure 4E). These results establish that multiple histone writers and readers can be engineered at gatekeeper sites to access orthogonal protein-protein interfaces.

To determine if the engineered writer and reader could act in tandem, we first benzylated full-length $\mathrm{H} 3$ and purified mononucleosomes using the Suv39H2 mutant followed by enrichment with the hole-modified CBX1. We observed a signal for H3 only in the presence of benzyl-SAM as evident from Western blot data (Figure S18), demonstrating successful reading and writing of $\mathrm{H} 3 \mathrm{~K} 9 \mathrm{bn}$ on full-length substrates.

We further investigated whether the orthogonal pairs are functional in a cellular milieu (Figure 5A, S19). HEK293T cells were cultured to express full-length hole-modified Suv39H2 variant, and the isolated nuclei were incubated with benzyl-SAM in a pulldown assay. Only the benzylated $\mathrm{H} 3$ was found to be specifically enriched with the CBX1 mutant (Figure S19), indicating that the engineered pair could act on chromosomal histone. Next, we expressed a full-length CBX1 variant carrying the engineered chromodomain. ${ }^{26}$ Nuclear extracts were incubated with biotinylated histone peptides, each carrying either unmodified, methylated or benzylated lysine, pulled down with avidin beads and analyzed using antibodies for CBX1, 3, or 5 (Figure 5B, S20). While the trimethylated peptide enriched all three wild-type CBX proteins, the benzylated bait was specific for hole-modified CBX1 (Figure 5B, S21). Furthermore, biotinylated peptides carrying methyllysine at a site different from $\mathrm{H} 3 \mathrm{~K} 9$ failed to interact with the mutant (Figure 5C, S21), confirming competency of the engineered system to mediate allele-specific histone-reader interactions. As we only examined CBX1, 3, and 5, detailed proteomic analysis of enriched proteins will be required to evaluate specificity of $\mathrm{H} 3 \mathrm{~K} 9 \mathrm{bn}$ across all the methyllysine readers.

Finally, we examined interactions between the CBX1 variant and transcriptional complexes (Figure 5A). Binding of full-length $\mathrm{CBX}$ proteins to $\mathrm{H} 3 \mathrm{~K} 9 \mathrm{me} 3$ creates a docking site for transcriptional regulators such as TIF1 $\beta .^{26,27}$ We incubated biotinylated H3K9bn peptide with nuclear extract of HEK293T cells expressing the "hole-modified" reader, and enriched the "interactome" using avidin and analyzed by Western blotting with TIF $1 \beta$ antibody (Figure 5D, S21). We observed selective pull-down of TIF1 $\beta$ by benzylated peptide, but not the unmodified peptide, only when cells expressed the "hole-modified" CBX1 mutant. The "bumped" peptide failed to interact with transcriptional regulators without the engineered reader. As a positive control, trimethylated peptide was shown to enrich TIF1 $\beta$ using endogenous CBX proteins. This set of results demonstrated that the engineered system maintains native-like interactions between a specific methyllysine reader and transcriptional regulators.

In summary, we offer a strategy to modulate protein-protein interactions particularly those governed by lysine methylation. Development of orthogonal pairs for protein-protein interactions is rarely attempted. ${ }^{28-30}$ Using a set of $\mathrm{H} 3 \mathrm{~K} 9 \mathrm{me} 3$ writers and readers as a paradigm, we showed that the remodeled interface is orthogonal to the wild type. We 
established biochemical integrity of the engineered interface, provided structural rationale for orthogonality, demonstrated generality of the approach, and validated functional compatibility of the synthetic interface in recognizing transcriptional regulators. We anticipate developing an in cellulo assay to synthesize benzyl-SAM by a promiscuous SAM synthetase mutant using benzyl methionine precursor. ${ }^{31}$ Such an engineered benzyllysine apparatus would allow installing the unique modification on chromosomal histone to interrogate a specific methyllysine pathway within cell for orthogonal manipulation of mammalian gene expression.

\section{Supplementary Material}

Refer to Web version on PubMed Central for supplementary material.

\section{ACKNOWLEDGMENTS}

We thank the University of Pittsburgh, the National Institutes of Health (R01GM123234), and the National Science Foundation (MCB-1817692) for financial support; Dr. D. Chakraborty and members of our laboratory for critical reading and editing of the paper. Support for MALDI-TOF MS instrumentation was provided by a grant from the National Science Foundation (CHE-1625002).

\section{REFERENCES}

(1). Kouzarides T Chromatin modifications and their function. Cell 2007, 128, 693-705. [PubMed: 17320507]

(2). Luo M Chemical and Biochemical Perspectives of Protein Lysine Methylation. Chem. Rev 2018, 118, 6656-6705. [PubMed: 29927582]

(3). Lin H S-Adenosylmethionine-dependent alkylation reactions: when are radical reactions used? Bioorg. Chem 2011, 39, 161-70. [PubMed: 21762947]

(4). Taverna SD; Li H; Ruthenburg AJ; Allis CD; Patel DJ How chromatin-binding modules interpret histone modifications: lessons from professional pocket pickers. Nat. Struct. Mol. Biol 2007, 14, 1025-40. [PubMed: 17984965]

(5). Patel DJ A Structural Perspective on Readout of Epigenetic Histone and DNA Methylation Marks. Cold Spring Harbor Perspect. Biol 2016, 8, No. a018754.

(6). Beaver JE; Waters ML Molecular Recognition of Lys and Arg Methylation. ACS Chem. Biol 2016, 11, 643-53. [PubMed: 26759915]

(7). Murn J; Shi Y The winding path of protein methylation research: milestones and new frontiers. Nat. Rev. Mol. Cell Biol 2017, 18, 517-527. [PubMed: 28512349]

(8). Arkin MR; Tang Y; Wells JA Small-molecule inhibitors of protein-protein interactions: progressing toward the reality. Chem. Biol 2014, 21, 1102-14. [PubMed: 25237857]

(9). James LI; Frye SV Chemical probes for methyl lysine reader domains. Curr. Opin. Chem. Biol 2016, 33, 135-41. [PubMed: 27348158]

(10). Milosevich N; Hof F Chemical Inhibitors of Epigenetic Methyllysine Reader Proteins. Biochemistry 2016, 55, 1570-83. [PubMed: 26650180]

(11). Islam K The Bump-and-Hole Tactic: Expanding the Scope of Chemical Genetics. Cell Chem. Biol 2018, 25, 1171-1184. [PubMed: 30078633]

(12). Belshaw PJ; Schoepfer JG; Liu K-Q; Morrison KL; Schreiber SL Rational Design of Orthogonal Receptor-Ligand Combinations. Angew. Chem., Int. Ed. Engl 1995, 34, 2129-2132.

(13). Bishop AC; Ubersax JA; Petsch DT; Matheos DP; Gray NS; Blethrow J; Shimizu E; Tsien JZ; Schultz PG; Rose MD; Wood JL; Morgan DO; Shokat KM A chemical switch for inhibitorsensitive alleles of any protein kinase. Nature 2000, 407, 395-401. [PubMed: 11014197]

(14). Baud MG; Lin-Shiao E; Cardote T; Tallant C; Pschibul A; Chan KH; Zengerle M; Garcia JR; Kwan TT; Ferguson FM; Ciulli A Chemical biology. A bump-and-hole approach to engineer 
controlled selectivity of BET bromodomain chemical probes. Science 2014, 346, 638-41. [PubMed: 25323695]

(15). Qiao Y; Molina H; Pandey A; Zhang J; Cole PA Chemical rescue of a mutant enzyme in living cells. Science 2006, 311, 1293-7. [PubMed: 16513984]

(16). Breski M; Dey D; Obringer S; Sudhamalla B; Islam K Engineering Biological C-H Functionalization Leads to Allele-Specific Regulation of Histone Demethylases. J. Am. Chem. Soc 2016, 138, 13505-13508. [PubMed: 27709909]

(17). Islam K; Zheng W; Yu H; Deng H; Luo M Expanding cofactor repertoire of protein lysine methyltransferase for substrate labeling. ACS Chem. Biol 2011, 6, 679-84. [PubMed: 21495674]

(18). Allis CD; Muir TW Spreading chromatin into chemical biology. ChemBioChem 2011, 12, 264 79. [PubMed: 21243714]

(19). Dalhoff C; Lukinavicius G; Klimasauskas S; Weinhold E Direct transfer of extended groups from synthetic cofactors by DNA methyltransferases. Nat. Chem. Biol 2006, 2, 31-2. [PubMed: 16408089]

(20). Lachner M; O’Carroll D; Rea S; Mechtler K; Jenuwein T Methylation of histone H3 lysine 9 creates a binding site for HP1 proteins. Nature 2001, 410, 116-20. [PubMed: 11242053]

(21). Kaustov L; Ouyang H; Amaya M; Lemak A; Nady N; Duan S; Wasney GA; Li Z; Vedadi M; Schapira M; Min J; Arrowsmith CH Recognition and specificity determinants of the human cbx chromodomains. J. Biol. Chem 2011, 286, 521-9. [PubMed: 21047797]

(22). Nielsen PR; Nietlispach D; Mott HR; Callaghan J; Bannister A; Kouzarides T; Murzin AG; Murzina NV; Laue ED Structure of the HP1 chromodomain bound to histone H3 methylated at lysine 9. Nature 2002, 416, 103-7. [PubMed: 11882902]

(23). Liu L; Zhen XT; Denton E; Marsden BD; Schapira M ChromoHub: a data hub for navigators of chromatin-mediated signalling. Bioinformatics 2012, 28, 2205-6. [PubMed: 22718786]

(24). Rea S; Eisenhaber F; O'Carroll D; Strahl BD; Sun ZW; Schmid M; Opravil S; Mechtler K; Ponting CP; Allis CD; Jenuwein T Regulation of chromatin structure by site-specific histone $\mathrm{H} 3$ methyltransferases. Nature 2000, 406, 593-9. [PubMed: 10949293]

(25). Canzio D; Larson A; Narlikar GJ Mechanisms of functional promiscuity by HP1 proteins. Trends Cell Biol. 2014, 24, 377-86. [PubMed: 24618358]

(26). Lechner MS; Schultz DC; Negorev D; Maul GG; Rauscher FJ 3rd, The mammalian heterochromatin protein 1 binds diverse nuclear proteins through a common motif that targets the chromoshadow domain. Biochem. Biophys. Res. Commun 2005, 331, 929-37. [PubMed: 15882967]

(27). Miyagi S; Koide S; Saraya A; Wendt GR; Oshima M; Konuma T; Yamazaki S; MochizukiKashio M; Nakajima-Takagi Y; Wang C; Chiba T; Kitabayashi I; Nakauchi H; Iwama A The TIF1beta-HP1 system maintains transcriptional integrity of hema-topoietic stem cells. Stem Cell Rep. 2014, 2, 145-52.

(28). Koh M; Nasertorabi F; Han GW; Stevens RC; Schultz PG Generation of an Orthogonal ProteinProtein Interface with a Noncanonical Amino Acid. J. Am. Chem. Soc 2017, 139, 5728-5731. [PubMed: 28413876]

(29). Palmer AE; Giacomello M; Kortemme T; Hires SA; Lev-Ram V; Baker D; Tsien RY Ca ${ }^{2+}$ indicators based on computationally redesigned calmodulin-peptide pairs. Chem. Biol 2006, 13, 521-30. [PubMed: 16720273]

(30). Rooklin D; Modell AE; Li H; Berdan V; Arora PS; Zhang Y Targeting Unoccupied Surfaces on Protein-Protein Interfaces. J. Am. Chem. Soc 2017, 139, 15560-15563. [PubMed: 28759230]

(31). Wang R; Islam K; Liu Y; Zheng W; Tang H; Lailler N; Blum G; Deng H; Luo M Profiling genome-wide chromatin methylation with engineered posttranslation apparatus within living cells. J. Am. Chem. Soc 2013, 135, 1048-56. [PubMed: 23244065] 


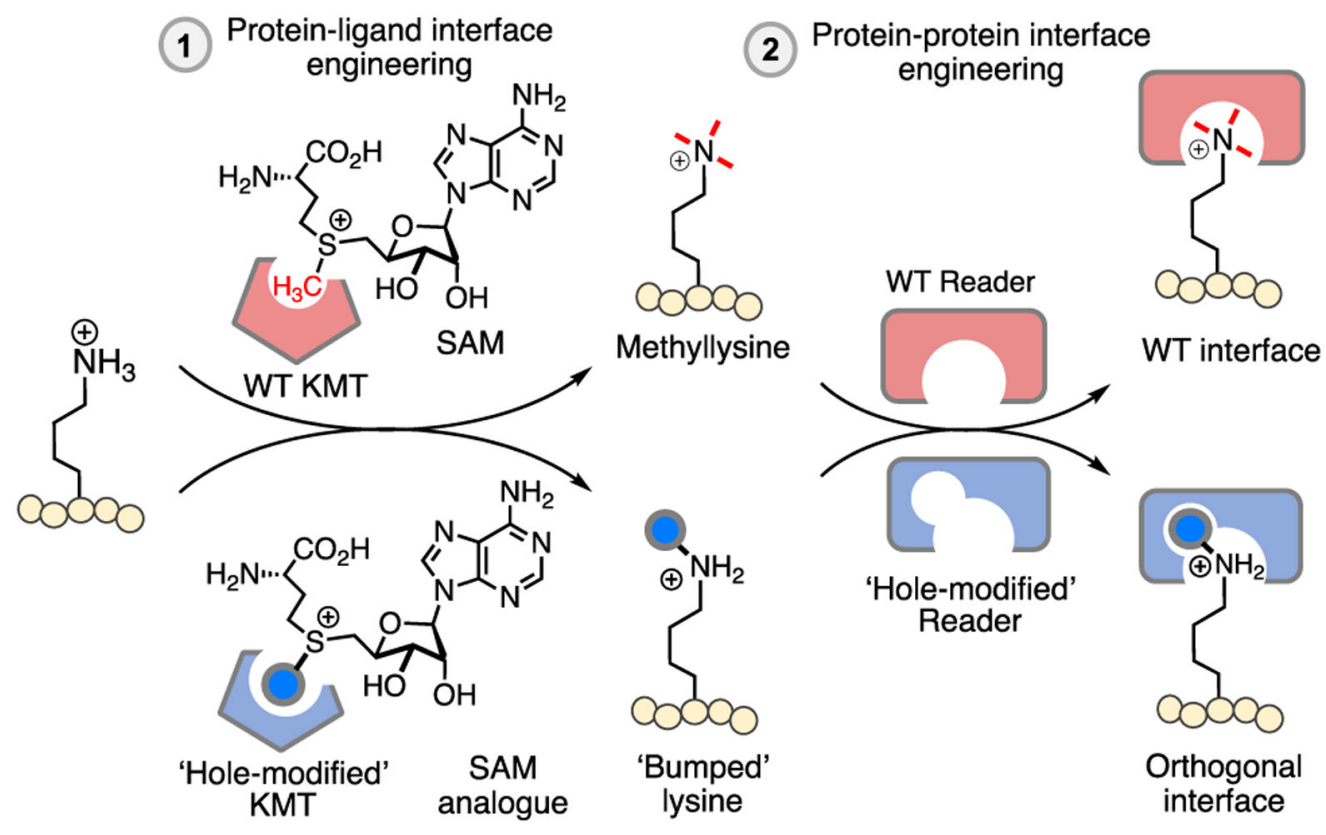

Figure 1.

Strategy for allele-specific protein-protein interactions. Methyllysine writer (KMT) is first engineered to introduce "bumped" lysine and disrupt interaction with wild-type readers. Binding is restored using "hole-modified" reader, allowing conditional manipulation of methyllysine pathways. 
A
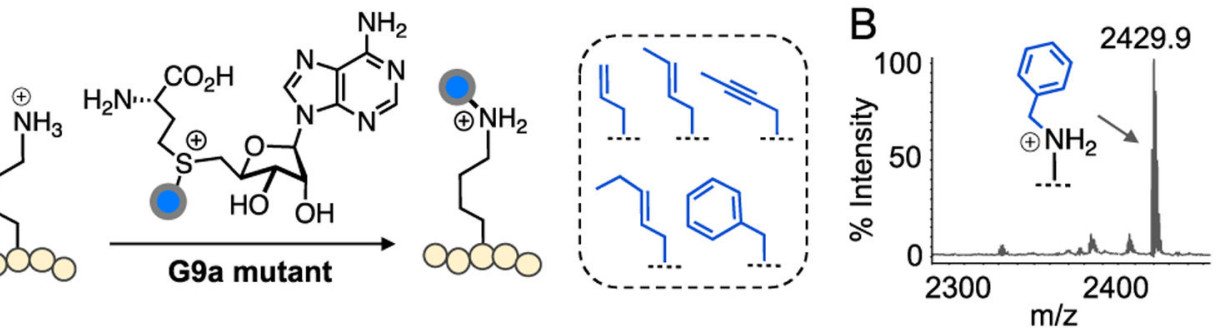

C

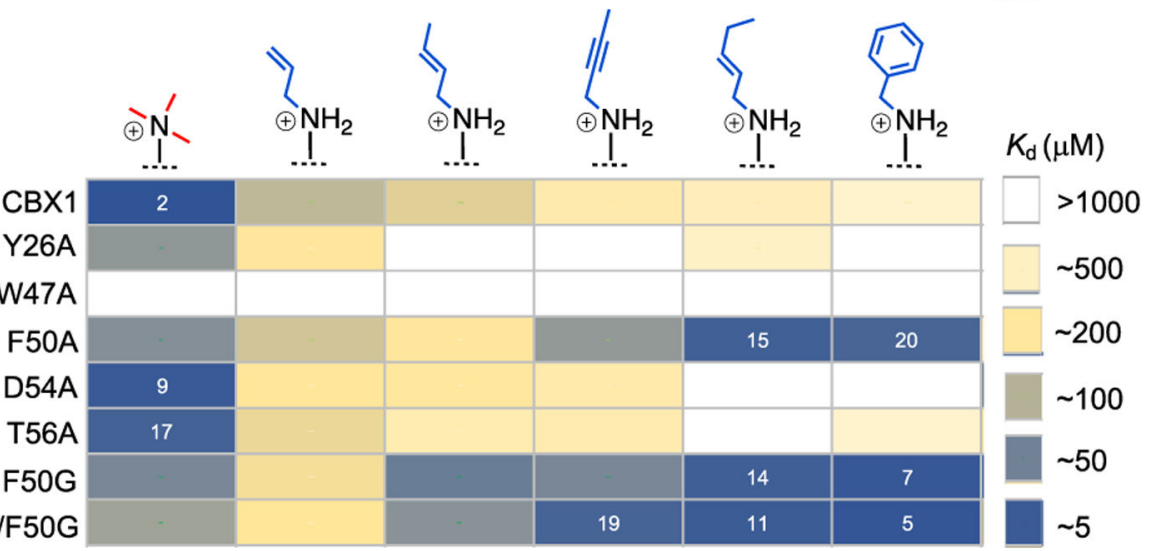

Figure 2.

Engineering of G9a and CBX1. (A) G9a-Y1154A mutant transfers alkenyl groups from the corresponding SAM analogues to TAMRA-labeled H3K9 peptide. (B) MALDI-MS showing benzylation of the substrate peptide by G9a-Y1154G mutant using benzyl-SAM. (C) Heatmap diagram showing dissociation constants $\left(K_{\mathrm{d}}\right)$ for the binding of modified H3K9 peptides by wild-type CBX1 and "hole-modified" mutants. 
A

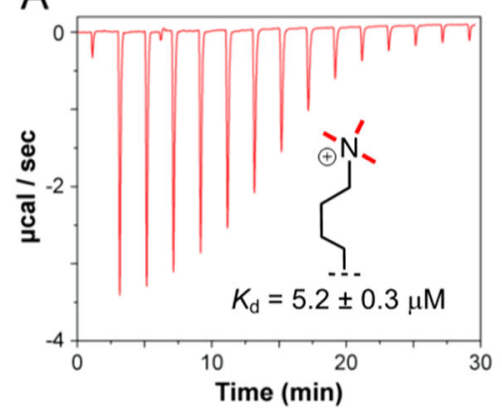

B

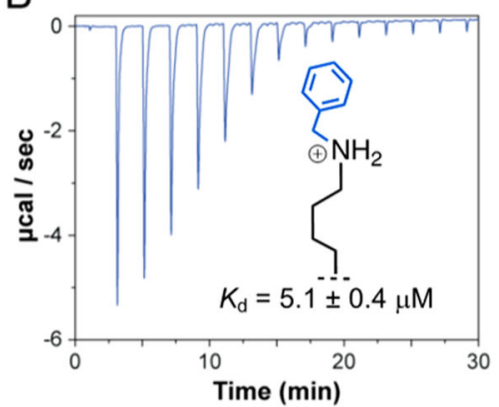

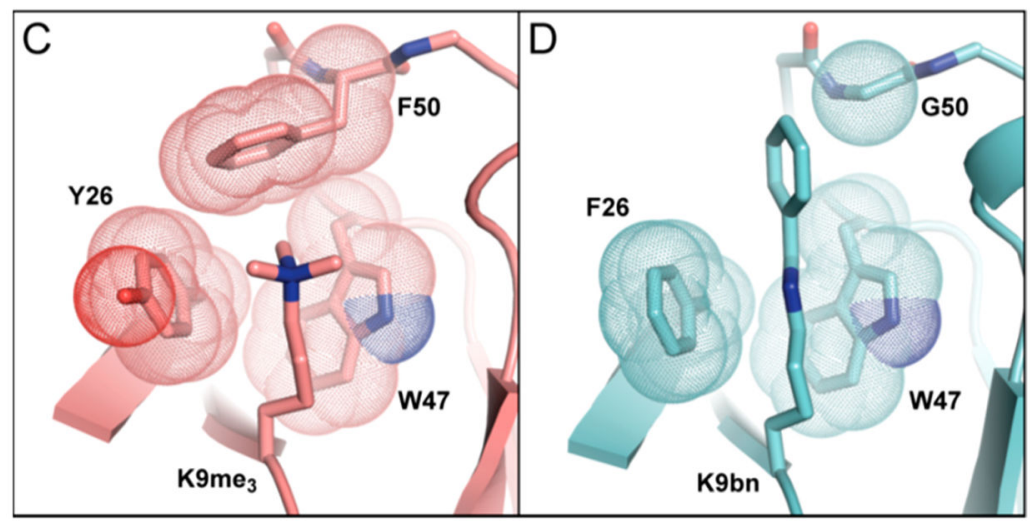

Figure 3.

Characterization of the histone-reader pairs. (A, B) Isothermal titration calorimetric (ITC) measurements for binding between wild-type CBX1 and H3K9me3 (A), and Y26F/F50GCBX1 and H3K9bn (B). (C, D) View of the aromatic cage from crystal structures of wildtype CBX1 chromodomain bound to $\mathrm{H} 3 \mathrm{~K} 9$ me3 peptide $(\mathrm{C})$ and "hole-modified" $\mathrm{CBX} 1$ (Y26F/F50G) bound to H3K9bn (D). 
A

$$
\begin{array}{ll}
\text { G9a } & \text { LGFDYGDRF } \\
\text { SUV39h1 } & \text { LTFDYNMQV } \\
\text { SUV39h2 } & \text { LTFDYQMKG } \\
\text { SUV420h1 } & \text { ISCYYGDGF } \\
\text { EZH1 } & \text { LFFDYRYSQ } \\
\text { EZH2 } & \text { LFFDYRYSQ } \\
\text { SETD2 } & \text { LTFDYQFQR } \\
\text { SETD8 } & \text { LLYDYGDRS } \\
\text { SMYD1 } & \text { LTVSYIDFL } \\
\text { SETMAR } & \text { LSYDYSGRY }
\end{array}
$$

B

$\begin{array}{ll}\text { CBX1 } & \text { KWKGFSDED } \\ \text { CBX3 } & \text { KWKGFTDAD } \\ \text { CBX5 } & \text { KWKGFSEEH } \\ \text { L3MBTL1 } & \text { FLVHFDNWD } \\ \text { TP53BP1 } & \text { YKLLFDDGY } \\ \text { BPTF } & \text { DTKLYCICK } \\ \text { EED } & \text { DENFYTCAW } \\ \text { DNMT3B } & \text { GFSWWPAMV } \\ \text { ZMYND11 } & \text { GFGFWPAKV } \\ \text { KDM4A } & \text { DGQVYGAKF }\end{array}$

D
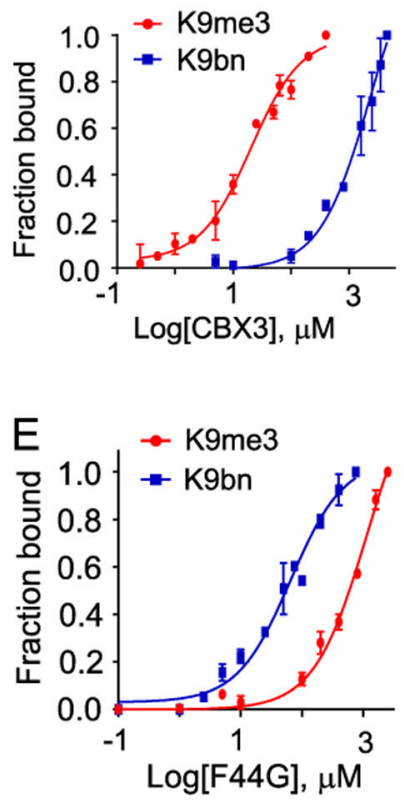

Figure 4.

Generality in methyllysine writer-reader engineering. (A, B) Sequence alignments of KMTs (A) and methyllysine readers (B) showing Y1154 of G9a and F50 in CBX1 are highly conserved. (C) Substrate benzylation by Suv39H2-Y372G mutant on full-length histone H3. (D) Binding of wild-type CBX3 toward H3K9me3 $\left(K_{\mathrm{d}}=12.2 \pm 0.2 \mu \mathrm{M}\right)$ and $\mathrm{H} 3 \mathrm{~K} 9 \mathrm{bn}\left(K_{\mathrm{d}}>\right.$ $1 \mathrm{mM})$. (E) Binding of CBX3-F44G mutant toward H3K9me3 $\left(K_{\mathrm{d}}>1 \mathrm{mM}\right)$ and H3K9bn $\left(K_{\mathrm{d}}=49 \pm 2.4 \mu \mathrm{M}\right)$. 

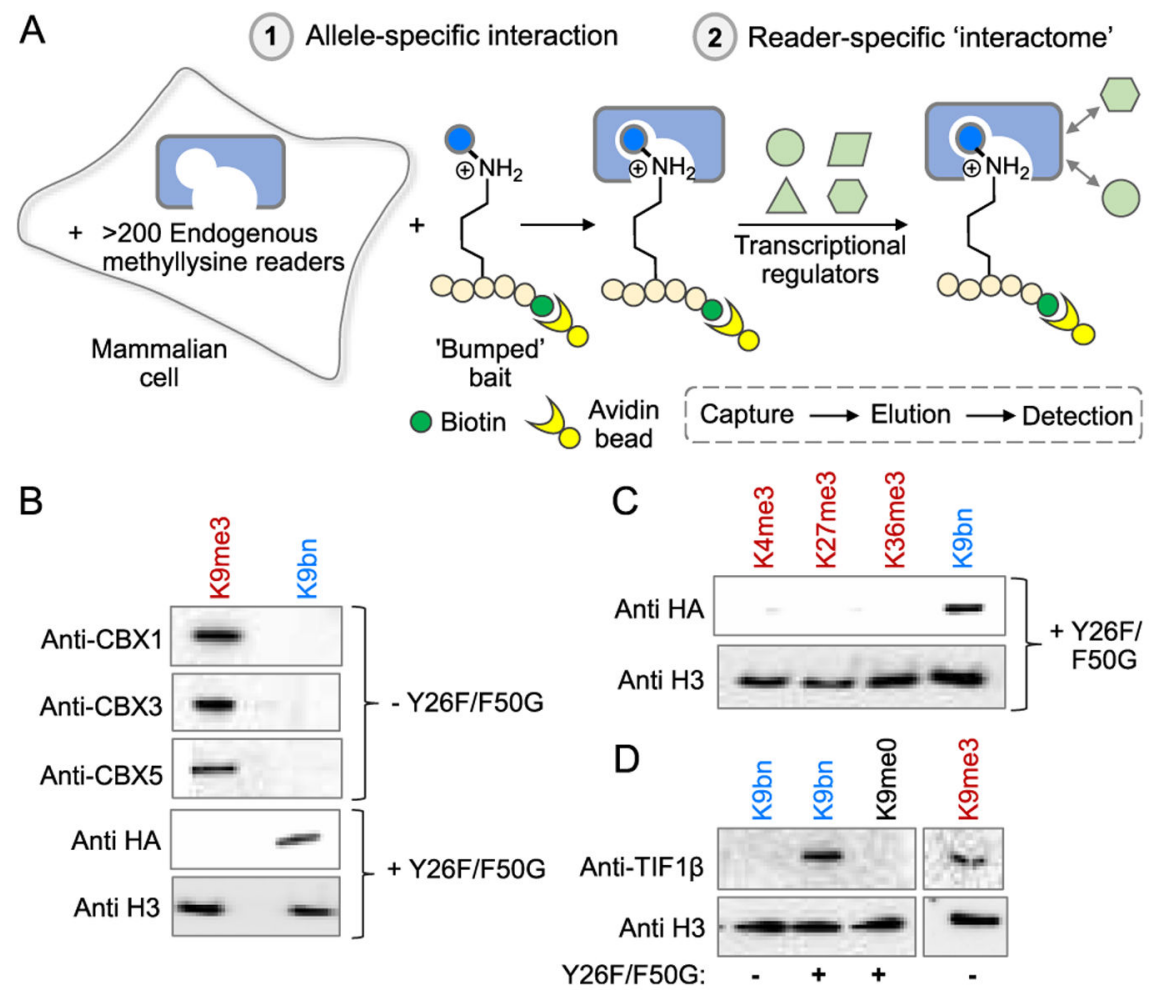

Figure 5.

Allele-specific interactions demonstrated in cell extracts. (A) Interaction between "holemodified" CBX1 and "bumped" histone in the presence of endogenous methyllysine readers (step 1). The engineered complex binds to transcriptional regulators (step 2). (B) Western blot (indicated antibody) of nuclear extracts pulled-down using biotin-attached H3K9me3 or H3K9bn peptide. CBX1 mutant carries HA tag. (C) Western blot (anti-HA antibody) of nuclear extracts pulled-down using biotin-attached H3K4me3, H3K27me3, H3K36me3 or H3K9bn peptide. (D) Western blot (anti-TIF1 $\beta$ antibody) of nuclear extracts pulled-down using biotin-attached $\mathrm{H} 3 \mathrm{~K} 9 \mathrm{me} 3$ or $\mathrm{H} 3 \mathrm{~K} 9 \mathrm{bn}$ or unmodified peptide. 